\title{
Cooperative Game Theory Based Load Balancing in Long Term Evolution Network
}

\author{
By \\ Sadia Intesar(ID:11101064) \\ Subarno Saha(ID:12121132) \\ Under the Supervision \\ of \\ Dr.Md.Muhidul Islam Khan
}

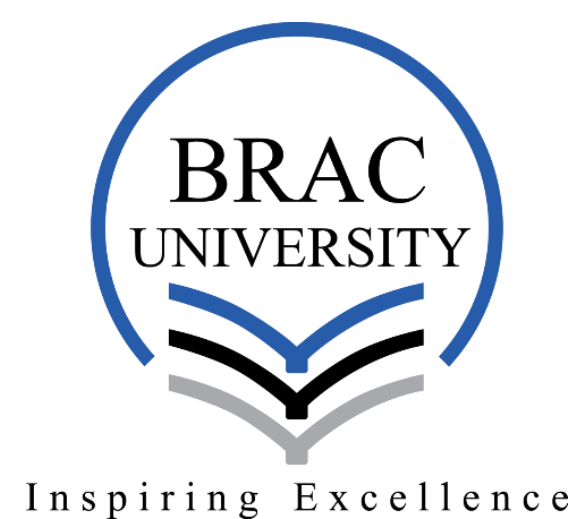

Department of Computer Science \& Engineering

School of Engineering \& Computer Science

BRAC University 


\section{Cooperative Game Theory Based Load Balancing in Long Term Evolution Network}

Thesis submitted in partial fulfillment of the requirement for the degree of

Bachelor of Science

In

Computer Science and Engineering and

Electrical and Electronic Engineering

Under the Supervision of

Dr.Md.Muhidul Islam Khan

By

Sadia Intesar(ID:11101064)

Subarno Saha(ID:12121132)

December 2015 


\section{DECLARATION}

We do hereby declare that the thesis titled "Cooperative Game Theory Based Load Balancing in Long Term Evolution Network" is submitted to the Department of Computer Science and Engineering of BRAC University in partial fulfillment of the completion of Bachelors of Science in Computer Science and Engineering and Electrical and Electronic Engineering. We hereby declare that this thesis is based on results obtained from our own work. Due acknowledgement has been made in the text to all other material used. This thesis, neither in whole nor in part has been previously submitted to any University or Institute for the award of any degree or diploma. The materials of work found by other researchers and sources are properly acknowledged and mentioned by reference.

Dated: 20 December 2015

Signature of Supervisor

Signature of Authors

Dr.Md.Muhidul Islam Khan

Sadia Intesar (11101064)

Assistant professor

Department of Computer Science and Engineering

BRAC University

Dhaka,Bangladesh

Subarno Saha(12121132) 


\section{FINAL READING APPROVAL}

\section{Thesis Title:}

Cooperative Game Theory Based Load Balancing in Long Term Evolution Network Date of Submission: $20^{\text {th }}$ December, 2015

The final report is satisfactory and it's all materials are also acceptable and ready for the submission to the Department of Computer Science and Engineering,BRAC University.

Signature of Supervisor

\section{Dr.Md.Muhidul Islam Khan}

Assistant professor

Department of Computer Science and Engineering

BRAC University

Dhaka,Bangladesh 


\section{PREFACE}

Numerous people have supported us during the development of this dissertation and our undergraduate experience more generally. A few words' mention here cannot adequately capture all our appreciation.

We are very thankful to our thesis coordinator Dr.Md.Muhidul Islam Khan, Assistant Professor, Department of Computer Science and Engineering, BRAC University for guiding us throughout our thesis work.

We would like to thank the following corporate people for their cooperation:

i. $\quad$ Md. Abir Ahmed, Senior Executive, HR \& Admin, Ranks Tel

ii. Nousheen S. Chowdhury, Market Development, Tahsina Rahman, Intern, Banglalink

iii. Fuad Hassan and Nishat Quamrul, Senior Executive, HR, Grameenphone

We are also grateful to A.K.M. Nivrito and Rajkin Hossain, Students of BRAC University for being with us throughout the thesis work.

Last but not least, we would like to thank our parents, our brothers and sisters, for all their enduring support and always believing in us.

Date: $20^{\text {th }}$ December 2015

Sadia Intesar

Subarno Saha 


\begin{abstract}
Long term evolution (LTE) network, incompatible with $2 \mathrm{G}$ and $3 \mathrm{G}$ networks is the most promising technology for wireless communication with higher speed and capacity. Selforganized load balancing is an important research issue for the wireless networks. Game theory provides an efficient way to provide self-organizing properties in a distributed environment like LTE networks. Load balancing means to assign users from highly loaded cells to neighbor lower loaded cells. The amount of load needs to be offloaded or accepted by a particular cell is not really specified and currently totally vendor specified. In our proposed cooperative game theoretic approach, each cell is considered as a player where they trade the load by forming a coalition by satisfying the overall performance of the network. Simulation results show that our proposed method provides better performance in terms of satisfied users and adjusted load values.
\end{abstract}

Index Terms - Cooperative game theory, Long term evolution network, eNodeBs, Load balancing, Physical resource blocks. 


\section{ABBREVIATION}

\begin{tabular}{|c|c|}
\hline eNodeB & Evolved NodeB \\
\hline HRPD & High Rate Packet Data \\
\hline HSPA & High Speed Packet Access \\
\hline ITU & International Telecommunication Union \\
\hline LTE & Long Term Evolution \\
\hline PRBs & Physical Resource Blocks \\
\hline SINR & Signal to Interference and Noise Ratio \\
\hline UE & User Equipment \\
\hline $3 \mathrm{G}$ & 3rd Generation \\
\hline 3GPP & 3rd Generation Partnership Project \\
\hline $4 \mathrm{G}$ & 4th Generation \\
\hline MME & Mobility management entity \\
\hline HSS & Home Subscriber Server \\
\hline S-GW & Serving Gateway \\
\hline APN & Access Point Name \\
\hline APN & Packet Data Network \\
\hline SGSN & Serving GPRS support node \\
\hline MME & Mobility Management Entity \\
\hline PCRF & Policy Control and Charging Rules Function \\
\hline PCEF & Policy Control Enforcement Function \\
\hline PDF & Policy Decision Function \\
\hline CRF & Charging Rules Function \\
\hline
\end{tabular}




\section{CONTENTS}

DECLARATION III

FINAL READING APPROVAL IV

PREFACE $\quad$ V

ABSTRACT

ABBREVIATION

CONTENTS

LIST OF FIGURES

CHAPTER 1

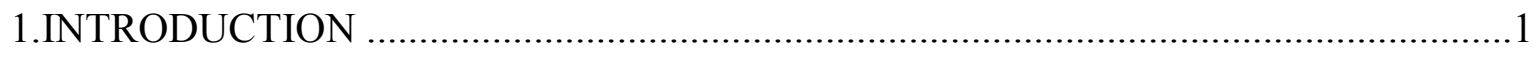

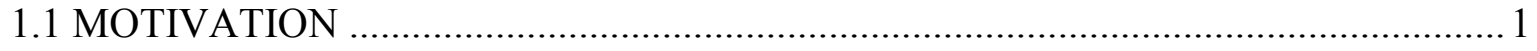

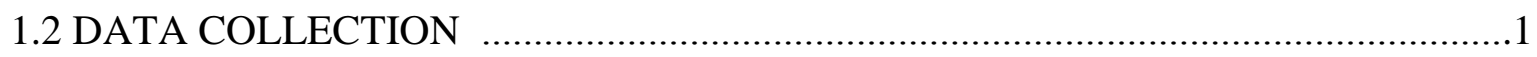

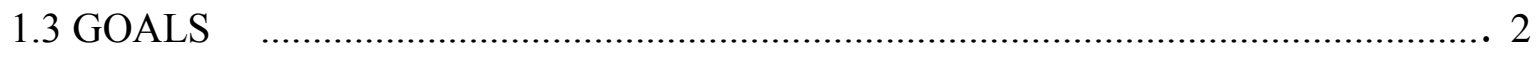

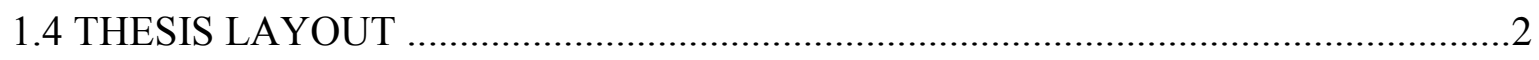

CHAPTER 2

2.RELATED WORKS ........................................................................................ 3

CHAPTER 3

3.GAME THEORY

3.1 CLASSIFICATION OF GAME THEORY ...................................................... 4

3.1.1 COOPERATIVE GAME THEORY ............................................................ 4

3.1.2 NONCOOPERATIVE GAME THEORY ......................................................... 4

3.2 COALITION GAME THEORY …............................................................... 5 


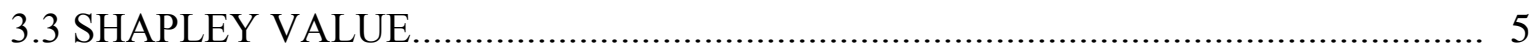

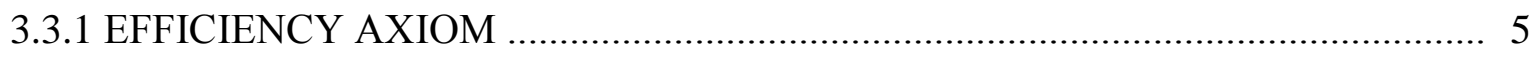

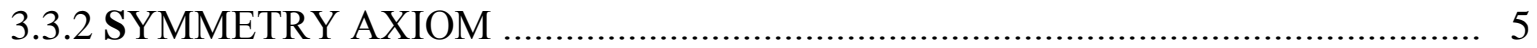

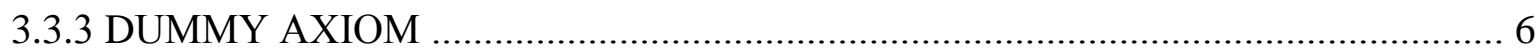

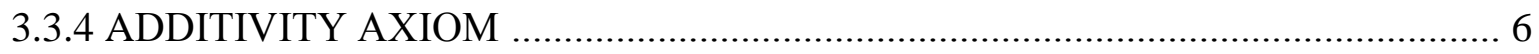

\section{CHAPTER 4}

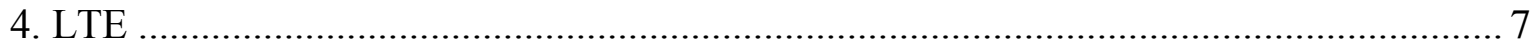

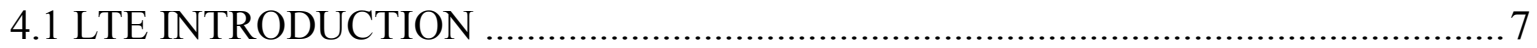

4.2 DIFFERENCE BETWEEN DIFFERENT WIRELESS COMMUNICATION .............. 7

4.3 LTE NETWORK ARCHITECTURE .......................................................................................................

4.3.1 THE USER EQUIPMENT ............................................................................................................................

4.3.2 THEE-UTRAN ..............................................................................................................................................9

4.3.3 THE EVOLVED PACKET CORE .................................................................................................................. 10

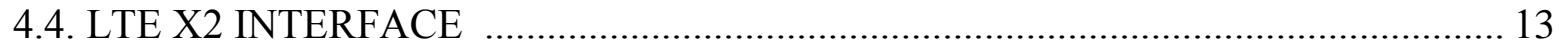

\section{CHAPTER 5}

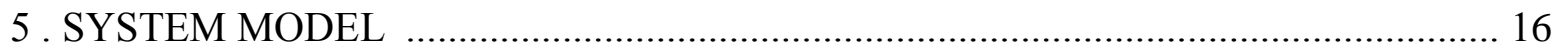

\section{CHAPTER 6}

6 .PROPOSED METHOD FOR LOAD BALANCING ............................................ 17

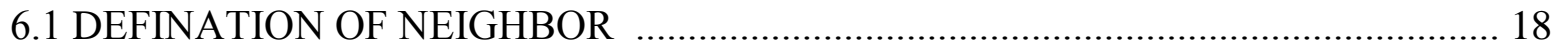

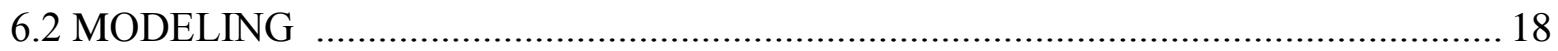

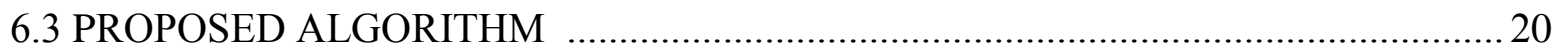

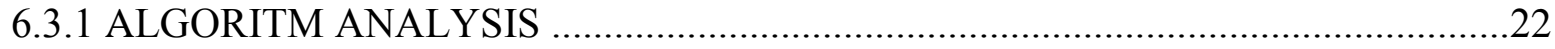


CHAPTER 7

7.1 EXPERIMENTAL RESULTS AND EVALUATION..................................... 24

7.1.1 SETTING OF PARAMETERS ............................................................... 24

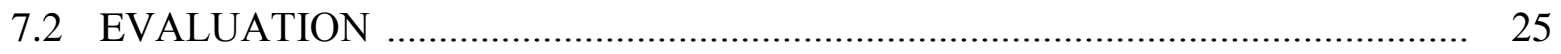

CHAPTER 8

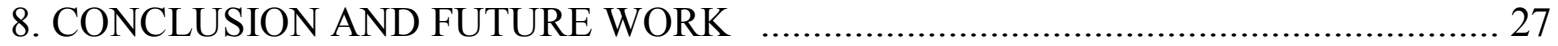

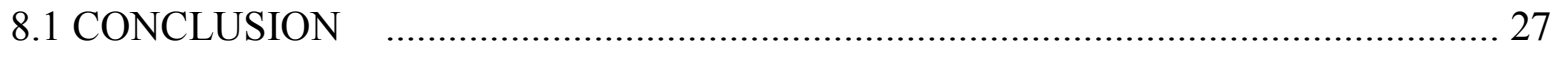

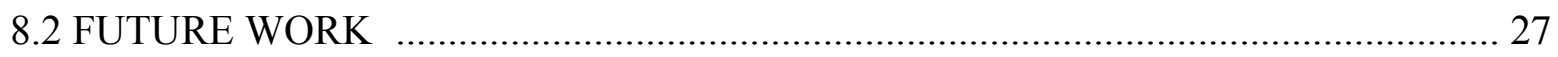

CHAPTER 9

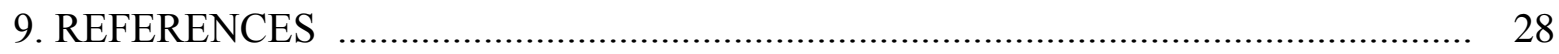

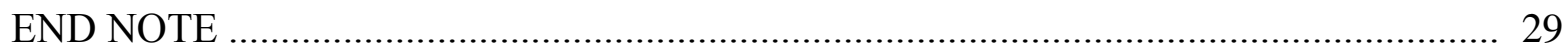




\section{LIST OF FIGURES}

Fig.1 LTE network architecture

Fig.2 X2 interface

Fig.3 Network model.

Fig.4 Bipartite graph for cells

Fig.5 Algorithm for load balancing

Fig.6 Notations for algorithm.

Fig.7 Unsatisfied user vs time

Fig.8 Load value vs time 


\section{CHAPTER 1}

\section{INTRODUCTION}

\subsection{MOTIVATION}

Long term evolution network (LTE) [13], [14] refers to the leading edge technology for mobile data communication with higher speed and capacity. LTE is often referred to wireless broadband. LTE is also referred to as 3GPP [15] long term evolution. 3GPP means third generation partnership project which is operated by the European Telecommunications Standards Institute. This is also known as LTE super $3 \mathrm{G}$ and LTE super 4G. With the recent advancement of $4 \mathrm{G}$ LTE networks, there has been increasing interest on the performance and power characteristics [16], [17].

Load balancing is the most efficient way to improve the performance of a network. Mobile users and their data usage provide an impact on the performance of the overall cellular networks. Data usage is random, time varying and unbalanced which causes unequal load scenarios in different cells of the network. Unequal load scenario makes some cells overloaded while, other cells have much less users. So, the resource is not fully utilized throughout the network [18]. In this scenario, the performance deteriorates a lot due to the lack of proper resource distribution. Typical cellular networks employ load balancing techniques by periodically exchanging information between neighboring cells which is totally vendor specific [16].

Recent research trend is to employ self-organizing algorithms to provide the proper load balancing. Self-organized load balancing algorithm helps to share the load information among neighboring cells autonomously. It also helps to offload the extra load from the overloaded cells to the under loaded cells.

Game theory provides the most efficient way to balance the load autonomously [7]. This is a self-organized technique for automatically adjusting the parameters of a distributed network. Game theory is now widely used for its self-organized properties to provide dynamic adaptation in a distributed network. We propose a cooperative game theory based algorithm for load balancing in a LTE network to provide better performance in terms of satisfied users and properly distributed loads.

\subsection{DATA COLLECTION}

Initially we started off with this particular topic as it was unique and has not been worked upon in details. As a result it has been difficult to collect online resources or refer to any previous 
work similar to our research. It is the first time that load balancing has been tackled with the following type of game theory namely Shapley value. Previously Nash Bargaining has been used to conduct similar research.

For the sole purpose of data collection we have visited a few leading network companies of Bangladesh. Unfortunately we could not get our hands on any specific data as many of the networking companies have not yet progressed towards the $4 \mathrm{G}$ connections. We faced this problem at the beginning of our research. As time went by companies such as Robi merged with Airtel and have started progressing towards Long Term Evolution networks. Other companies such as Grameenphone, a part of Telenor, have been working on this upgrade for a while now. Unfortunately they were unable to provide any data as it was confidential. Unlike the North American countries here in our country these load based data are not available online as a result we have had to work on assumed data mostly.

The data that we were able to collect was from Ranks Tel. This would have been very useful if we had not faced another obstacle. The data was of the 2G/GSM type. Making it difficult for is to use the data directly. Even then we tried to use a few figures to help us assume numbers that seem more reliable. Also at Ranks Tel they tend to have $100 \%$ efficiency rate which means that even at peak hours their congestion rate is zero or below. We are working on getting congestion rate to negative numbers but as the process is an extremely expensive process only large network companies are heading towards 4G LTE networks.

Lastly throughout these hurdles we have been able to conduct our research and complete it seamlessly so we are very grateful. Once the work is refined more and original data can be accessed the findings of this research would help to reduce a lot of networking problems such as call drops when put to practical use.

\subsection{GOALS}

Our goal is to provide an efficient way for load balancing which is self-organized. The idea is to consider the cellular networks cell as player. Most of the existing works consider the player as rational which tries selfishly to maximize its own reward. This non cooperative way is not suitable for the network for its overall performance. Our goal is to provide a cooperative and self-organized way for load balancing in a LTE network.

\subsection{THESIS LAYOUT}

The rest of this paper is organized as follows.

Chapter 2 discusses related work. Chapter3 is on game theory. Chapter 4 LTE basic concepts. Chapter 5 explains our system model. In chapter 6 we present our proposed method. Chapter 7 discusses experimental results and evaluation for a LTE network. Chapter 8 concludes this paper with a brief summary and future work. 


\section{CHAPTER 2}

\section{2 . RELATED WORKS}

\subsection{LTE NETWORK PRESENT AND HISTORY}

In distributed networks, the goal is to build a collaborative environment for facilitating the effective usage of resources [8]. LTE is a distributed cellular network where effective usage of resources is an important research issue. Load balancing is the key factor to maintain the resources of the network in a way that the performance is maximized. Most of the existing load balancing techniques does not provide self-organizing properties.

The 3GPP LTE Release 9 [21] provides the way of exchanging information between two neighboring cells by an interface. This work does not provide any self-organizing algorithms for load balancing and does not mention the amount of load that an overloaded cell should offload and an under loaded cell should accept. This is specifically implemented in eNodeB and hence it is very much vendor specified. In [22], the load balancing algorithm is proposed for the LTE network. Here, it is assumed that the amount of load needs to be offloaded from the overloaded cells which are fully aware. It is suitable for the case where eNodeBs of different vendors are working.

The studies on load balancing in LTE are mostly focused on adjusting the reselection/handover parameters to handle unequal traffic [29]. Standards have been made by 3GPP LTE to offload the overload cells. The load balancing use case was agreed on by RAN3 and introduced in 3GPP TR 36.902 [30], where the exchange of load information over X2 decision is agreed by RAN3. Some organizations, like project SOCRATES [31], and NGMN [32], have analyzed the application requirements on ALB and made some drafts. Lots of research in the area of load balancing in cellular network is processing. The traditional approach for load balancing algorithm is based on mid-and-long term forecasting, to find the overloaded base station and to adjust related parameters for load balancing.

\subsection{GAME THEORETIC APPROACH}

\subsubsection{NON-COOPERATIVE APPROACH}

There are a few studies on game theoretic models and algorithms for load balancing in distributed systems. Some of these involve non cooperative games. Orda et al. [36] studied a non-cooperative game in a network of parallel links with convex cost functions. They studied the existence and uniqueness of the Nash equilibrium. Altman et al. [37] investigated the same problem in a network of parallel links with linear cost functions. 
Roughgarden [35] formulated the load balancing problem as a Stackelberg game. In this type of noncooperative game one player acts as a leader and the rest as followers. He showed that it is NP-hard to compute the optimal Stackelberg strategy and presents efficient algorithms to compute strategies inducing near optimal solutions. Routing traffic in networks is a closely related problem which was studied from a game theoretic perspective.

Kameda et al. [34] studied non-cooperative games and derived load balancing algorithms for both single class and multi-class job distributed systems. For single class job systems they proposed an algorithm for computing the Wardrop equilibrium.

In [16] and [23], game theoretic approaches are proposed for the load balancing in a homogeneous network. In these methods, cells are considered as a rational player who deals with the load using game theoretic approach. But this non cooperative method makes the cell selfish to maximize its own reward. So, it is often possible that the performance of a particular cell may be improved but the overall performance of the network can be deteriorated.

Mavronicolas and Spirakis [38] derived tight bounds on coordination ratio in the case of fully mixed strategies where each user assigns its traffic with non-zero probability to every link.

\subsubsection{COOPERATIVE APPROACH}

Cooperative method helps to provide cooperation among cells to maximize the overall performance of the network. There are other works that focus on radio access or $4 \mathrm{G}$ Wimax that have worked on cooperative approach. An example is a [33] which focuses on the network selection decision problem and challenges, a comprehensive classification of related game theoretic approaches and a discussion on the application of game theory to the network selection problem faced by the next generation of $4 \mathrm{G}$ wireless networks.

To our best knowledge, there is no existing work that proposed cooperative game theoretic approach for load balancing. We propose a cooperative game theoretic approach, Shapely value [24] by forming a coalition among cells of a LTE network.

This paper proposes a cooperative game theoretic approach for load balancing which helps to balance the load by calculating the Shapely value among the neighboring cells, forming a coalition among them. Simulation results show that the performance is improved in terms of satisfied users by improving the load balancing across the network. 


\section{CHAPTER 3}

\section{GAME THEORY}

Game theory is the study of mathemathical models which defines how and why to make decision.It is the study of conflict and cooperation[1].In other words we could also say that game theory is concerned with decision making in strategic situations, where one must factor the preferences and rational choices of other players into their own decision to make the best choice for themselves. Game theoretic concepts apply whenever the actions of several elements are interdependent. These elements may be individuals, groups, firms, or any combination of these [1]. Game theoretical methods turn into frequent in numerous design programs, especially with communication engineering. With the emergence of cooperation as a new communication paradigm, along with the self-organizing, decentralized, autonomic networks, it has become imperative to seek suitable game theoretical tools that allow analyzing and studying the behavior and interactions of the nodes in future communication networks [2].

The general motivation for approaching a problem with a game theoretic approach is that the computational resources are distributed and used by many users having different requirements and also the players are likely to behave in a selfish manner and their behavior cannot be characterized using conventional techniques.

\subsection{CLASSIFICATION OF GAME THEORY}

Game theory is divided into two parts, cooperative and non cooperative.

\subsubsection{COOPERATIVE GAME THEORY}

Cooperative means cooperation. In a cooperative game,players negotiate with other players in the same game so that everyone can get profit and can make joint strategies[27]. The cooperative theory abstracts away from this level of detail, and describes only the outcomes that result when the players come together in different combinations[28].

\subsubsection{NONCOOPERATIVE GAME THEORY}

In a noncooperative game there is no form of negotiation. The highest bidder will will win the game[28]. 


\subsection{COALITION GAME THEORY}

A coalition game is the process of working together by forming a group of finite players(or agents) rather than working individualy. From a set of agents, coalition game theory defines how well each group (or coalition) of players can do for itself.Coalition game theory defines which coalition will form and how should that coalition divide its payoff (or utility) amongs its members.

In a coalition game there are $\mathrm{N}$ number of finite players which forms a coalition and $\mathrm{v}$ is the utility function of a coalition game $\mathrm{v}: 2^{\mathrm{N}} \rightarrow \mathbb{R}$ associate with each coalition $\mathrm{S} \subseteq \mathrm{N}$, then the payoff is $\mathrm{v}(\mathrm{S})$, that the coalitions members can distribute among themselves.For an empty set of coalition we assume $\mathrm{v}(\Phi)=0$

\subsection{SHAPLEY VALUE}

Shapley et al. [7] proposed a cooperative solution for the distribution of load balancing among finite players based on their marginal contribution.in this concept all the players in the coalition will receive payments or shares based on their contributions to each possible coalition. The Shapley value applies primarily in situations when the contributions of each actor are unequal. The Shapley value ensures each actor gains as much or more as they would have from acting independently. Shapley value is a solution concept which can associate with every coalitional game $(\mathrm{N}, \mathrm{v})$ a unique payoff vector known as the value of the game (which is quite different from the value of a coalition). Shapley approached this problem axiomatically by defining a set of desirable properties and he characterized a unique mapping $\varphi$. Shapley provided four axioms as follows ( $\varphi_{\mathrm{i}}$ is the payoff given to player $\mathrm{i}$ by the Shapley value $\varphi$ ).

\subsubsection{EFFICIENCY AXIOM}

All players precisely distribute among themselves the resources available to the grand coalition.

$$
\sum_{i}^{N} \varphi_{\mathrm{i}}(\mathrm{v})=\mathrm{v}(\mathrm{N}) .
$$

\subsubsection{SYMMETRY AXIOM}

If player $i$ and player $j$ are such that $\mathrm{v}(\mathrm{S} \cup\{i\})=\mathrm{v}(\mathrm{S} \cup\{j\})$ for every coalition $\mathrm{S}$ not containing player $i$ and player $j$, then

$$
\varphi_{\mathrm{i}}(\mathrm{v})=\varphi j(\mathrm{v}) .
$$

The symmetry axiom requires symmetric players to be paid equal shares. 


\subsubsection{DUMMY AXIOM}

A player will get zero payoff if it's marginal contribution is null with respect to every coalition.If player $i$ is such that $\mathrm{v}(\mathrm{S})=\mathrm{v}(\mathrm{S} \cup\{i\})$ for every coalition $\mathrm{S}$ not containing $i$, then

$$
\varphi_{\mathrm{i}}(\mathrm{v})=0 .
$$

\subsubsection{ADDITIVITY AXIOM}

If $\mathrm{u}$ and $\mathrm{v}$ are characteristic functions, then

$$
\varphi(\mathrm{u}+\mathrm{v})=\varphi(\mathrm{v}+\mathrm{u})=\varphi(\mathrm{u})+\varphi(\mathrm{v}) .
$$

For every game $(\mathrm{N}, \mathrm{v})$, the Shapley value $\varphi$ assigns a unique payoff allocation in $\mathrm{R} \in \mathrm{N}$ which satisfies the four axioms. The efficiency axiom is in fact group rationality. The symmetry axiom implies that, when two players have the same contribution in a coalition, their assigned payoffs must be equal. The dummy axiom assigns no payoff to players that do not improve the value of any coalition. Finally, the additivity axiom links the value of different games $u$ and $v$ and asserts that $\varphi$ is a unique mapping over the space of all coalitional games.

The Shapley value has an unique process to inspire the players to join in the grand coalition of $\mathrm{N}$ players.The payoff allocatted by Shapley Value to a player i $\epsilon \mathrm{N}$ is the expected marginal contribution of player i when it joins in the grand coalition. The payoff function or the expected marginal contribution of Shapley Value for each player $i$ is given as

$$
\varphi_{\mathrm{i}}(\mathrm{N}, \mathrm{v})=\frac{1}{N} \sum_{S \subseteq N\{i\}}|S| !(|N|-|S|-1) ![v(s)-v(s \cup\{i\})]
$$

For $\mathrm{n}$ players, the set of coalition, $2^{\mathrm{N}}$;here $\mathrm{i}$ is the index for each player, $\mathrm{N}$ is the set of $\mathrm{n}$ players.The formula can be interpreted as follows. If a player is added to the set $\mathrm{S}$, his contribution is $[\mathrm{v}(\mathrm{S})-\mathrm{v}(\mathrm{S} \cup\{\mathrm{i}\})]$, the marginal contribution of $i$ to coalition $S$, where $v(S)$ is the value including $i$ and $v(S \cup i)$ the value of contribution to $|S|$ without $i$. Multiply this quantity by the $|S|$ ! Different ways the set $\mathrm{S}$ could have been formed prior to agent i's addition and by the $(|\mathrm{N}|-|\mathrm{S}|-1)$ ! Different ways the remaining agents could be added afterward.Then sum over all

possible sets $S . \frac{1}{N !}$ denotes that each player should take the average of this contribution for different permutation in which the coalition can form. 


\section{CHAPTER 4}

\section{LTE (LONG TERM EVOLUTION NETWORK)}

\subsection{LTE INTRODUCTION}

LTE, Long Term Evolution Network, a 4G standard,was started as a project known as the 3rd generation partnership project (3GPP,earliar known as UMTS)in 2004.LTE evolved was evolved from the GSM,Global System for Mobile Communications.

LTE is a standard for wireless communication with high-speed data rate.It is based on GSM/EDGE and UMTS/HSPA network technologies and uses new modulation technique for increasing the capacity and managing faster mobility problem.LTE reduces the transfer latency compared to the $3 \mathrm{G}$ architecture by designing the IP-based system.

\subsection{DIFFERENCE BETWEEN WIRELESS COMMUNICATIONS}

$1 \mathrm{G}:$

Its is a standard of 1 st generation cellular network. It can only transfer data(voice data only) in a analog wave with no encription and poor sound quality.

2G:

$2 \mathrm{G}$ stands for second generation standard.It came with an enhanced privacy (only for voice data)and digital modulation technique to overcome the $1 \mathrm{G}$ limitations.

2.5G:

This standard came up with a new service like SMS (Short messaging service). EDGE, GPRS, HPCS (High Speed Circuit Switched) data.

3G:

$3 \mathrm{G}$ is a third generation mobile communication standard.It supports speech and data services simultaneously with a data rate of $2 \mathrm{Mbps}$. WCDMA,Ev-DO, and HSPA are the technologies under $3 \mathrm{G}$ standar 
4G:

4G is a fourth generation of cellular standards which supports ultra broadcast internet access,IP telephony.WIMAX and LTE are the two technologies of LTE.

\subsection{LTE NETWORK ARCHITECTURE}

The high-level network architecture of LTE is comprised of following three main components[20]:

- The User Equipment (UE).

- The Evolved UMTS Terrestrial Radio Access Network (E-UTRAN).

- The Evolved Packet Core (EPC).

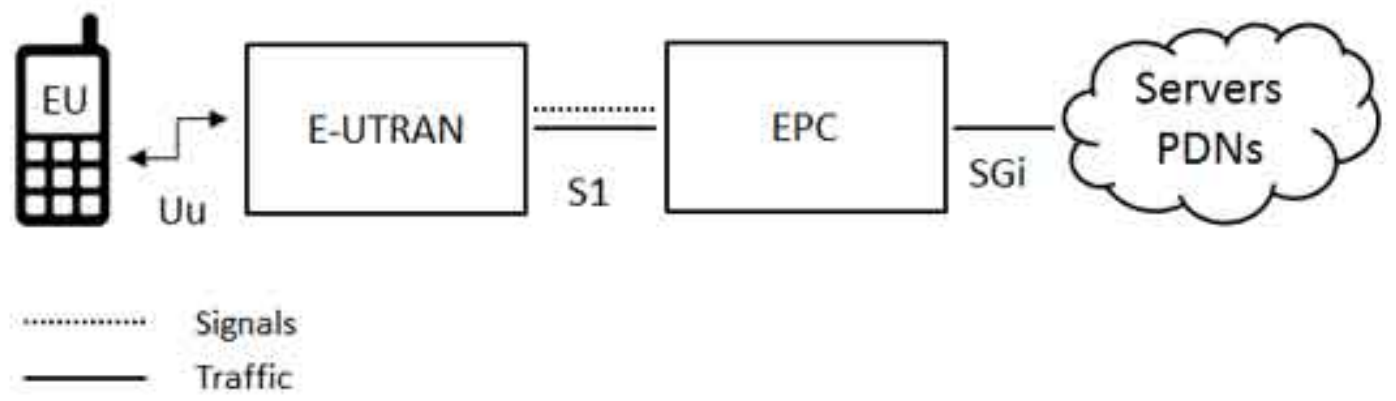

Fig.1 LTE network architecture

The evolved packet core communicates with packet data networks in the outside world such as the internet, private corporate networks or the IP multimedia subsystem.

\subsubsection{THE USER EQUIPMENT (EU)}

The internal architecture of the user equipment for LTE is identical to the one used by UMTS and GSM. To make the design more modular the UE is divided into two logical parts, Mobile Equipment (ME) and the User Subscriber Identity Module (USIM). The mobile equipment comprised of the following important modules: 
- Mobile Termination (MT): This handles all the communication functions such as radio transmission termination, authentication, and mobility management.

- Terminal Equipment (TE): This terminates the data streams by managing the hardware such as the speaker, microphones, video cameras and user display.

- Universal Integrated Circuit Card (UICC): This is also known as the SIM card for LTE equipment. It runs an application known as the Universal Subscriber Identity Module (USIM).

A USIM stores user-specific data very similar to 3G SIM card. This keeps information about the user's phone number, home network identity and security keys etc. The USIM contains the permanent identity of the user, the shared secret key, phone book and a host of other information.

\subsubsection{THE E-UTRAN (The access network)}

Initially the UTRAN architecture was made to sync very well with the 2G/GSM Access Network concepts. The general architecture followed the star model, meaning that a single controller controlled a large number of radio Base Stations (the Node B) over the IUB interface. Compared with UTRAN, the E-UTRAN OFDM-based structure is quite simple. It is only composed of one network element: the anode (for evolved Node B.). The architecture of evolved UMTS Terrestrial Radio Access Network (E-UTRAN) has been illustrated below [20].

The E-UTRAN handles the radio communications between the mobile and the evolved packet core and just has one component, the evolved base stations, called eNodeB or eNB. An eNB provides users with the radio interfaces and performs Radio Resource Management functions such as dynamic resource allocation (scheduler), eNB measurement configuration and provision, radio admission control, connection mobility control and Radio Bearer (RB) and Inter-Cell Interference Coordination (ICIC). These points are directly connected to network routers. There is no more intermediate controlling node. This has the advantage of simpler network architecture (fewer nodes of different types, which means simplified network operation) and allows better performance over the radio interface. Each eNB is a base station that controls the mobiles in one or more cells. The base station that is communicating with a mobile is known as its serving eNB. 
LTE Mobile communicates with just one base station and one cell at a time and there are following two main functions supported by eNB:

- The eNB sends and receives radio transmissions to all the mobiles using the analogue and digital signal processing functions of the LTE air interface.

- The eNB controls the low-level operation of all its mobiles, by sending them signaling messages such as handover commands.

Each e connects with the EPC by means of the S1 interface and it can also be connected to nearby base stations by the X2 interface, which is mainly used for signaling and packet forwarding during handover.

The EPC (Evolved Packet Core) is composed of several functional entities:

· The MME (Mobility Management Entity)

- The HSS (Home Subscriber Server)

- The Serving Gateway.

- The PDN Gateway (Packet Data Network).

- The PCRF (Policy and Charging Rules Function) Server.

The detailed description of all these are given below.

The X2 interface can be defined between eNodeB, working in a meshed way. In other words all node Bs can be linked together. The main purpose of this interface is to minimize packet loss due to user mobility. As the terminal moves across the access network, unsent or unacknowledged packets stored in the old eNodeB queues can be forwarded or tunneled to the new eNodeB. This can be noted down as the advantage of this interface.

Another kind of a base station is a home eNB (HeNB) that has been purchased by a user to provide femtocell coverage within the home. A home eNB belongs to a closed subscriber group (CSG) and can only be accessed by mobiles with a USIM that also belongs to the closed subscriber group. 


\subsubsection{THE EVOLVED PACKET CORE (EPC)}

The architecture of Evolved Packet Core (EPC) is comprised of many components. Some of the components like the Earthquake and Tsunami Warning System (ETWS), the Equipment Identity Register (EIR) and Policy Control and Charging Rules Function (PCRF) have not been described in details below in order to keep it simple and easy to understand.

The Home Subscriber Server (HSS) component has been carried forward from UMTS and GSM and is a central database that contains information about all the network operator's subscribers. The HSS is the concatenation of the HLR (Home Location Register) and the AuC (Authentication Center) - two functions being already present in pre-IMS 2G/GSM and 3G/UMTS networks. The HLR part of the HSS is in charge of storing and updating when necessary the database containing all the user subscription information, including:

- User identification and addressing - this corresponds to the IMSI (International Mobile Subscriber Identity) and MSISDN (Mobile Subscriber ISDN Number) or mobile telephone number.

- User profile information - this includes service subscription states and user-subscribed Quality of Service information (such as maximum allowed bit rate or allowed traffic class).

The AuC part of the HSS is in charge of generating security information from user identity keys. This security information is provided to the HLR and further communicated to other entities in the network. Security information is mainly used for:

- Mutual network-terminal authentication.

- Radio path ciphering and integrity protection, to ensure data and signaling transmitted between the network and the terminal is neither eavesdropped nor altered.

The Packet Data Network (PDN) Gateway (P-GW) communicates with the outside world i.e. packet data networks PDN, using SGi interface. Each packet data network is identified by an access point name (APN). The PDN gateway has the same role as the GPRS support node (GGSN) and the serving GPRS support node (SGSN) with UMTS and GSM. It can be said that the PDN gateway is the termination point of the packet data interface towards the Packet 
Data Network. As an anchor point for sessions towards the external Packet Data Networks, the PDN GW also supports Policy Enforcement features (which apply operator-defined rules for resource allocation and usage) as well as packet filtering (like deep packet inspection for virus signature detection) and evolved charging support (like per URL charging).

The serving gateway ( $\mathrm{S}-\mathrm{GW})$ acts as a router, and forwards data between the base station and the PDN gateway. From a functional perspective, the Serving GW is the termination point of the packet data interface towards E-UTRAN. When terminals move across eNodeB in E-UTRAN, the Serving GW serves as a local mobility anchor, meaning that packets are routed through this point for intra E-UTRAN mobility and mobility with other 3GPP technologies, such as 2G/GSM and 3G/UMTS.

The mobility management entity (MME) controls the high-level operation of the mobile by means of signaling messages and Home Subscriber Server (HSS). It is in charge of all the Control plane functions related to subscriber and session management. From that perspective, the MME supports the following:

- Security procedures - this relates to end-user authentication as well as initiation and negotiation of ciphering and integrity protection algorithms.

- . Terminal-to-network session handling - this relates to all the signaling procedures used to set up Packet Data context and negotiate associated parameters like the Quality of Service.

- Idle terminal location management - this relates to the tracking area update process used in order for the network to be able to join terminals in case of incoming sessions.

The MME is linked through the S6 interface to the HSS which supports the database containing all the user subscription information.

The Policy Control and Charging Rules Function (PCRF) is a component is responsible for policy control decision-making, as well as for controlling the flow-based charging functionalities in the Policy Control Enforcement Function (PCEF), which resides in the P-GW. The PCRF's main function is that its server manages the service policy and sends QoS setting information for each user session and accounting rule information. The PCRF Server combines functionalities for the following two UMTS nodes:

- The Policy Decision Function (PDF) 
- The Charging Rules Function (CRF)

The PDF is the network entity where the policy decisions are made. As the IMS session is being set up, SIP signaling containing media requirements are exchanged between the terminal and the P-CSCF. At some time in the session establishment process, the PDF receives those requirements from the $\mathrm{P}-\mathrm{CSCF}$ and makes decisions based on network operator rules, such as:

- Allowing or rejecting the media request.

- Using new or existing PDP context for an incoming media request.

- Checking the allocation of new resources against the maximum authorized

The CRFs role is to provide operator-defined charging rules applicable to each service data flow. The CRF selects the relevant charging rules based on information provided by the P-CSCF, such as Application Identifier, Type of Stream (audio, video, etc.), Application Data Rate, etc.

\subsection{LTE X2 INTERFACE}

The $\mathrm{X} 2$ interface is the interface between the eNodeBs.

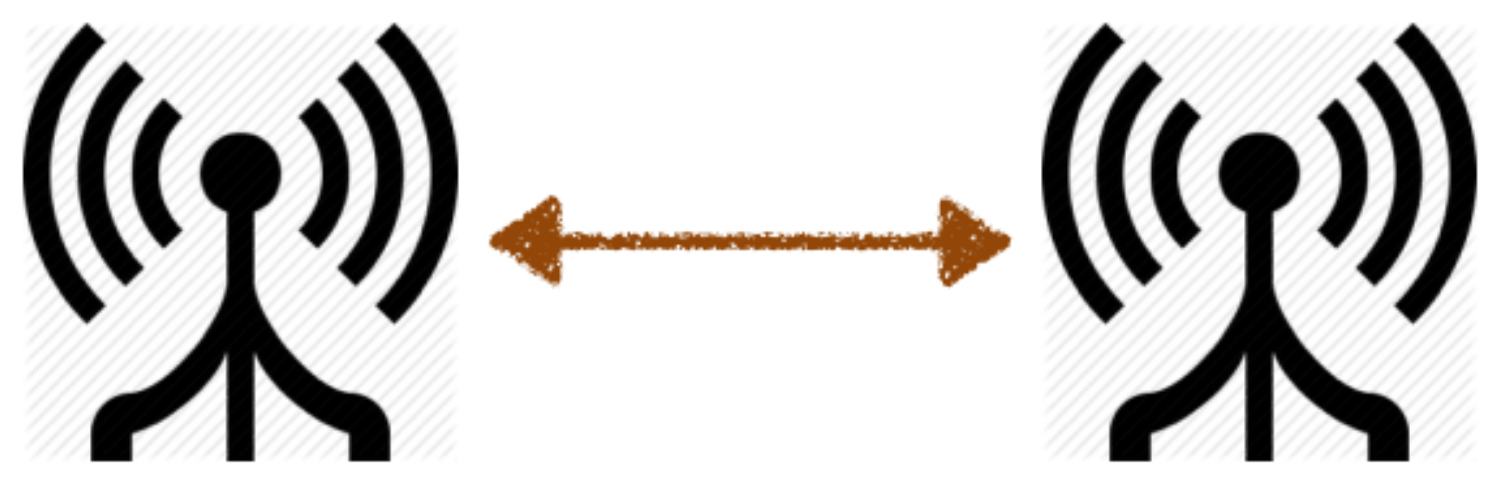

Fig. 2 X2 interface

The X2 interface supports exchange of information between eNodeBs to perform the following functions:

- Handover: mobility of UEs between eNodeBs 
- Load Management: sharing of information to help spread loads more evenly

- CoMP (Co-ordinated Multi-Point transmission or reception): Neighboring eNodeBs coordinate over X2 to reduce interference levels

- Network Optimization

- eNB configuration update, cell activation, including neighbor list updates

- Mobility Optimization: co-ordination of handover parameters

- General Management: initializing and resetting the X2

The X2 interface facilitates the exchange of load information. Thus it is a very important part of load balancing [20]. This interface has several main functionalities. The functionality flow is in the following order

eNodeB configuration update
( exchange served cell information" and "Number of
Antenna Ports")



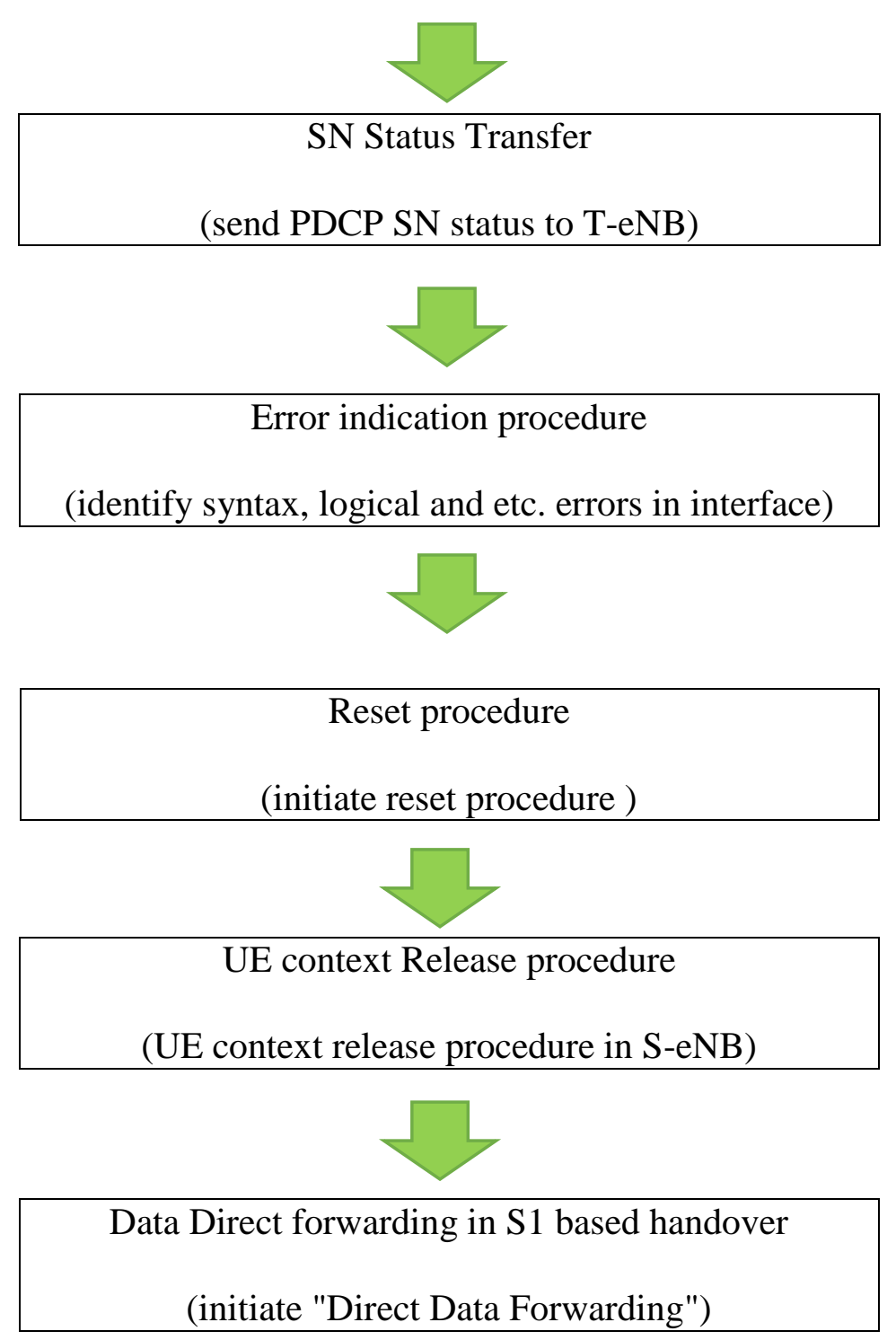


\section{CHAPTER 5}

\section{5 . SYSTEM MODEL}

The eNodeB allocates the physical resource blocks (PRBs) to all users by using a scheduling function. This scheduling function will be based on signal-to-noise ratio (SINR) of every user and resources that are used in user equipment (UEs).

An eNodeB is an element of LTE radio access network and is optimized to deploy for smaller coverage than macro eNodeB, such as indoor premises. The unit of resource allocation in LTE air interface is called a PRB.

Let the average data rate per user, $u$ is denoted by $D u$ and the data rate per PRB is given by $R$ (SINR) of user, $u$. Best load balancing can be achieved by Shannon's theorem [17]

$$
R(\operatorname{SINR})=\log 2\left(1+\operatorname{SINR}_{u}\right)
$$

Load generated (amount of PRBs required by user, $u$ ) by each user for the required data rate $D u$ is

$$
N u=\frac{D u}{R(S I N R) B W}
$$

Here, $B W$ is the transmission rate of one PRBs per frame. The load of a cell, $c$ can be expressed as

$$
\rho_{\mathrm{c}}=\operatorname{Min}\left[\frac{1}{\mathrm{Ntot}} \sum_{\mathrm{u} \mid \mathrm{X}(\mathrm{u})} \mathrm{Nu}, 1\right]
$$

Here, $\mathrm{N}_{\text {tot }}$ is the total number of PRBs of a cell. $X(u)$ is the connection function which gives the serving cell, $c$ for user, $u$.

Due to the resource limitations, number of unsatisfied user increases. When $\rho_{c} \leq 1$ user will be satisfied, otherwise unsatisfied. If, $\rho \mathrm{c}=N$, it satisfies only $\frac{1}{N}$ users [16]. Then, the number of satisfied user of a network can be expressed as

$$
\mathrm{Z}=\sum_{\forall c} \max \left(0, U c\left(1-\frac{1}{\rho c}\right)\right)
$$

where number of users in a cell, $c$ is denoted as $U_{c}$. 


\section{CHAPTER 6}

\section{6 . PROPOSED METHOD FOR LOAD BALANCING}

We consider a cellular coverage area, $c$ consists of $n$ cells where, $c=\left\{c_{1}, c_{2}, c_{3}, c_{4}, \ldots, c_{n}\right\}$ which are participating in the coalition. For a overloaded cell, $\rho_{c}>1$. The overloaded cell gets all possible information from its connected UEs about the reference signal received power (RSRP) levels not only for the serving cells but also for the neighboring cells having a strong signal level [12].

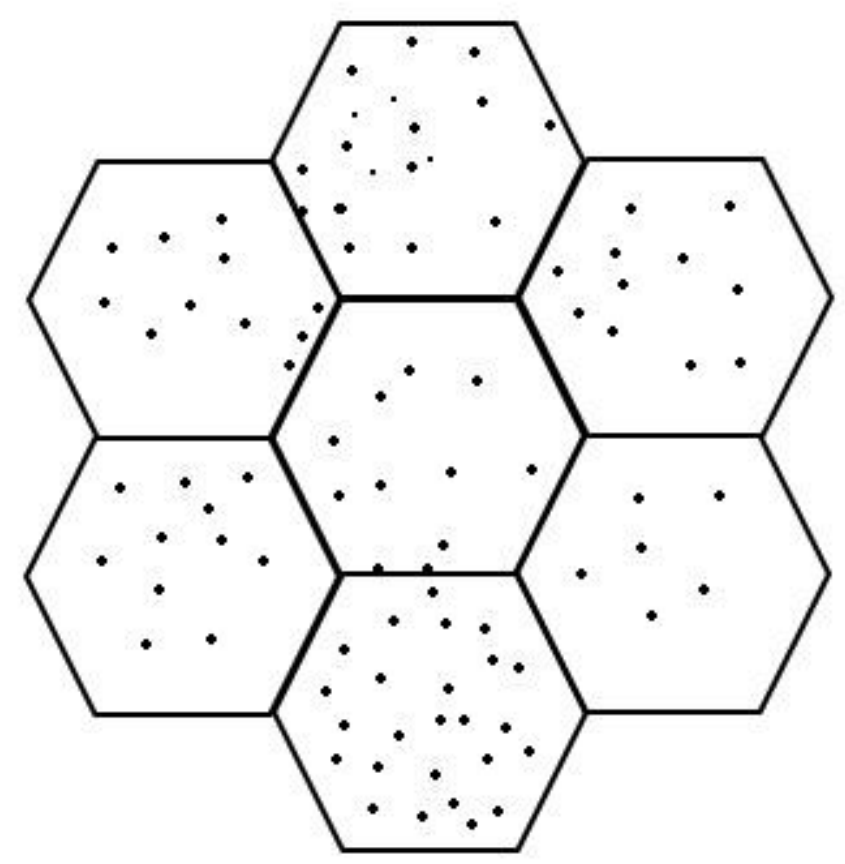

Fig. 3. Network model.

During a cell selection, cell reselection or handover an UE usually selects the cell based on RSRP which is the average power measured on UEs for cell specific reference signal [16].The link imbalance value, which is defined as the difference in the RSRP levels of overloaded cell, $o$ and the neighboring under loaded cell, $i$ is

$$
\triangle R S R P_{u, i}=R S R P_{u, o}-R S R P u_{, i}
$$

A good or optimum RSRP value provides good SINR value which determines a good signal strength of a cell to the UEs [24].The coalition that involves the under loaded cells, maximizes the satisfaction based on their marginal contribution in a fairly distribution manner. Each under loaded cell receives load from its neighboring overloaded cells. Using Shapley Value (described 
in subsection 3.3) each cell in the coalition receives or donate loads based on their marginal contribution. The utility function of the overloaded cell, $o$ and the under loaded cell, $i$ is denoted as

$$
\begin{array}{ll}
\text { Utilityo }=U o-\Delta X o & \text { if } 0 \leq \rho \leq 1 \\
\text { Utilityo }=\frac{U o-\Delta X o}{\rho} & \text { otherwise. } \\
\text { Utilityi }=U i+\Delta X i & \text { if } 0 \leq \rho \leq 1 \\
\text { Utilityi }=\frac{U i+\Delta X i}{\rho} & \text { otherwise. }
\end{array}
$$

Here, $\Delta X i$ is the load value that represents how much load will be added to the underloaded cell and $\triangle X o$ is the load that will be given out from the overloaded cell. For load balancing first we calculate each cell's obtained value by using

$$
\Delta X c, i=L c, i-S c, i ; \quad \forall c, i
$$

Where, $\Delta X_{c, i}$ is the obtained value of each $i^{\text {th }}$ cell, $L_{c, i}$ is the load value before Shapley Value calculation. $S_{c, i}$ is the Shapley Value of each cell. We notice in simulation that some cell's obtained values are positive and some cell's obtained values are negative. Positive is for the overloaded cell and negative value is for the under loaded cell.

\subsection{DEFINATION OF NEIGHBOR}

When the signs of the obtained values, $\Delta X$ in Equation 10 are opposite for two cells and the cells meet the threshold value of SINR will be considered as neighbor cells.

\subsection{MODELING}

Now we design a Bipartite graph for those cells. Positive obtained value carrier cells are on the left partition and negative obtained value carrier cells on the right partition.

In Figure 2 a circle defines a cell and edges define neighboring cells. The value inside the circle defines the id of cells and the values outside the circles indicate the obtained value of the corresponding cells. Initially none of the obtained values are zero, because we are only considering the cells with the positive and negative obtained values. Any cell's obtained value is zero means particular cell is satisfied in a cooperative manner. After modeling we use our own greedy algorithm for maximizing the number of satisfied cells. If any cell fails to satisfy itself then we will try to make that cell's obtained value close to zero by losing or gaining some loads. But unfortunately, few cell's obtained value remain unchanged forever because of insufficient number of neighbor of that cell. Our first priority is to maximize the number of satisfied cell and the second priority is to maximize the number of cell's obtained value more close to zero. 


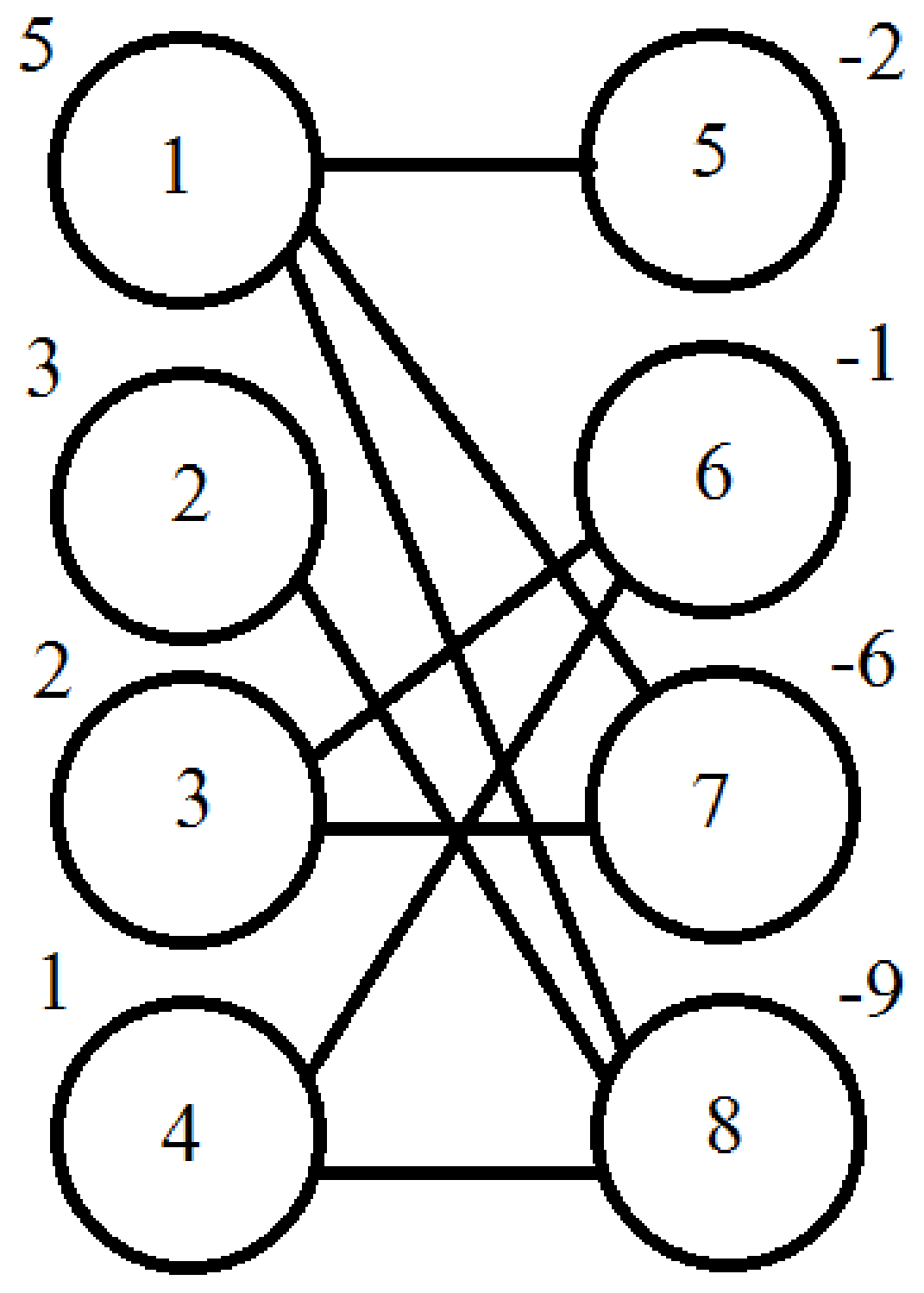

Fig. 4 Bipartite graph for cells 


\subsection{PROPOSED ALGORITHM}

Algorithm 1 Proposed algorithm for load balancing.

1: Model Bipartite Graph $(\mathrm{G})$ of cells

2: Assign obtained values of cells in $\operatorname{Array}(\mathrm{O})$

3: Sort the positive obtained value carrier cells in ascending order

4: for Each cell $u \in$ positive obtained value cells do

5: $\quad$ Sort all cells $v \in G \cdot \operatorname{Adj}[u]$ in descending order

6: for Each vertex $v \in$ G.Adj $[u]$ do

7: $\quad$ if $(\mathrm{O}[\mathrm{u}]>$ absolute $(\mathrm{O}[\mathrm{v}]))$ then

8: $\quad \mathrm{O}[\mathrm{u}]=\mathrm{O}[\mathrm{u}]-\operatorname{absolute}(\mathrm{O}[\mathrm{v}])$

9: $\mathrm{O}[\mathrm{v}]=0$

10: $\quad$ Remove cell $\mathrm{id}->\mathrm{V}$ and remove all the edges connecting to that cell from Bipartite $\operatorname{Graph}(\mathrm{G})$

11: $\quad$ else if $(\mathrm{O}[\mathrm{u}]<\operatorname{absolute}(\mathrm{O}[\mathrm{v}]))$ then

12: $\mathrm{O}[\mathrm{v}]=\mathrm{O}[\mathrm{v}]+\mathrm{O}[\mathrm{u}]$

13: $\mathrm{O}[\mathrm{u}]=0$

14: $\quad$ Remove cell id $->\mathrm{u}$ and remove all the edges connecting to that cell from Bipartite Graph $(\mathrm{G})$

15: $\quad$ break

16: $\quad$ else

17: $\mathrm{O}[\mathrm{u}]=0$

18: $\quad \mathrm{O}[\mathrm{v}]=0$

19: $\quad$ Remove cell $\mathrm{id}->\mathrm{u}, \mathrm{v}$ and remove all the edges connecting to that cells

from Bipartite $\operatorname{Graph}(\mathrm{G})$

20: break

21: $\quad$ end if

22: $\quad$ end for

23: end for 
Considering the algorithm 1 and the bipartite graph in Figure 2, all the cells in left side are arranged in ascending order of their obtained values from bottom to top. We try to make those cells satisfied or more close to satisfied where obtained values are more close to zero. We take that particular cell's neighboring cells from right side in descending order because we also need to make those satisfied or more close to satisfied. So, for each operation, we give the maximum possible loads from left side cell to its neighboring cell then the obtained values of both cells will be closer to zero which is closer to be satisfied. Here, actually for each operation at least one of the cells must be satisfied. For each operation, we remove the satisfied cell from the bipartite graph. If both cells satisfied in each operation, we will remove both satisfied cells from the bipartite graph. If a cell in left side becomes satisfied then we go to the next left side cell instead of seeing other neighboring cells because that particular cell already becomes satisfied. So it cannot make satisfy any other cells because if it gives its remaining cells to its neighbor then it becomes unsatisfied. But if that left side cell is not satisfied then we continue to see its next neighboring cells because its previous neighboring cell becomes satisfied but not itself. So, it has a chance to satisfy its self if it has any neighboring cell exist. If it has no longer any neighboring cells exist and it is not satisfied still now, it will remain unsatisfied cell forever. We will go to the next left side cell to operate that same process. In this way maximum possible number of cells will be satisfied and also maximum number of possible cell's obtained value will be more close to zero.
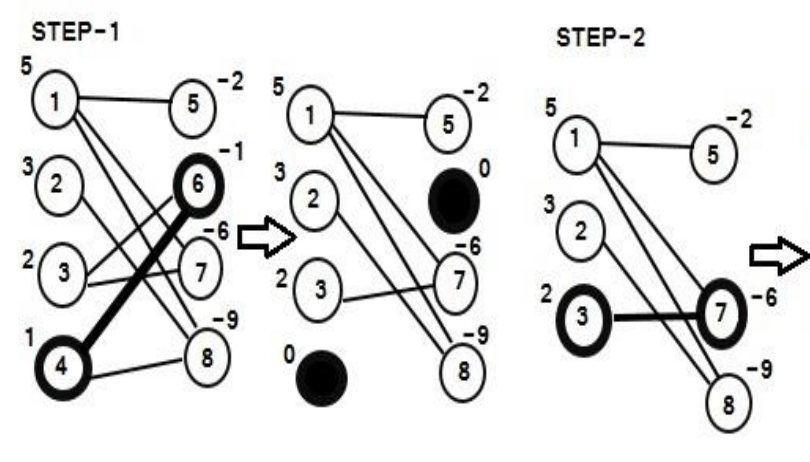

STEP-4

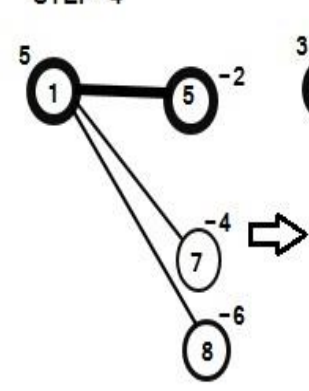

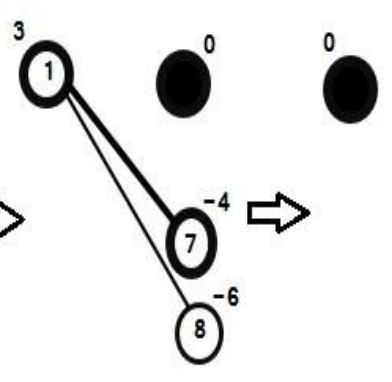

STEP-3
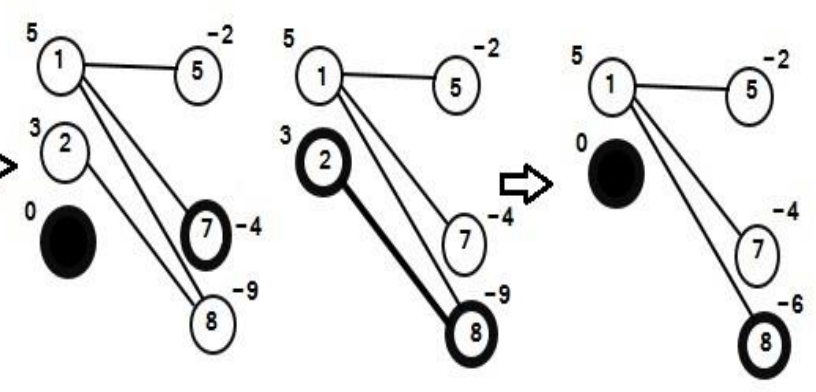

Fig. 5. Algorithm for load balancing. 


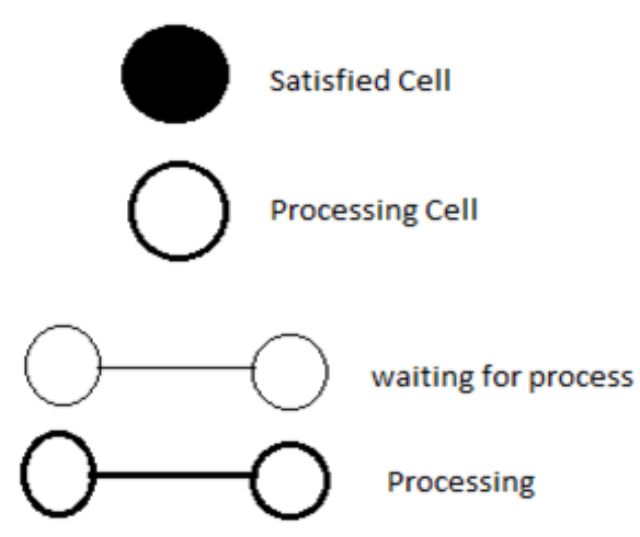

Fig. 6. Notations for algorithm.

\subsubsection{ALGORITHM ANALYSIS}

Figure 3 shows the steps about how the algorithm works. Here is a particular scenario of some cells forming a bipartite graph. Figure 4 shows the notations used to describe the algorithm in Figure 3. Applying the algorithm 1 in Figure 3, we find how it works. In each step if any cell becomes satisfied, it is marked as bold and it will be removed from the bipartite graph. All of its edges will also be removed. In Step 1, the operation works for cell id 4 and 6 . As they have equal absolute obtained values, both cells obtained value will become zero by giving and taking equal number of obtained value. So both cells become satisfied.

In Step 2, the operation works for cell id 3 and 7 . As cell id 7 has greater absolute obtained value than cell id 3, cell id 3 obtained value will become zero which denotes cell id 3 becomes satisfied and by giving all its obtained value to cell id 7 . Cell id 7 obtained value will become more close to zero which is -4 from the previous value -6 .

In Step 3, the operation works for cell id 2 and 8 . As cell id 8 has more absolute obtained value than cell id 2, cell id 2 obtained value will become zero which denotes cell id 2 becomes satisfied by giving all its obtained value to cell id 8 . Cell id 8 obtained value will become more close to zero which is -6 from the previous value -9 .

In Step 4, the operation works for cell id 1 and 5 but here cell id 5 has less absolute obtained value than cell id 1 . So cell id 5 obtained value will become zero by taking 2 obtained value from cell id 1 . Cell id 5 becomes satisfied. The next operation will be between cell id 1 and 7 . As cell id 7 has greater absolute obtained value than cell id 1, cell id 1 obtained value will be zero and becomes satisfied. Cell id 7 obtained value will be more close to zero which is -1 from the previous value -4 .

In the final step, as no unsatisfied left side cells exist, the algorithm terminates and there are two unsatisfied cells remained. The unsatisfied cell ids are 7 and 8 where both have improved their values from the previous values. 


\section{CHAPTER 7}

\section{EXPERIMENTAL RESULTS AND EVALUATION}

\subsection{SETTING OF PARAMETERS}

For simulation we have chosen the homogeneous network with 19 sites, 3 sectors per site.That means total 57 cells in the network.In all simulation we use default values for the parameters mentioned in Table I.

TABLE I : CONSIDERED PARAMETER

\begin{tabular}{|l|l|}
\hline Parameter & Value \\
\hline Network layout & $19 \mathrm{BS}$ site,3 sectors,57 cells \\
\hline $\mathrm{N}_{\text {tot }}$ & $50 \mathrm{PRBs}$ \\
\hline Carrier frequency & $2 \mathrm{GHz}$ \\
\hline Bandwidth & $20 \mathrm{MHz}$ \\
\hline Shadowing & zero mean and standard deviation $8 \mathrm{~dB}$ \\
\hline Packet Scheduler & Round Robin \\
\hline enodeB TX power & $40 \mathrm{~W}$ \\
\hline Thermal Noise Power & $-114 \mathrm{dBm}$ \\
\hline Sub-carrier per RB & 12 \\
\hline Sub-carrier Spacing & $15 \mathrm{KHz}$ \\
\hline Threshold load, $\rho_{\text {th }}$ & 0.85 \\
\hline$\Delta$ RSRP & \\
\hline $\mathrm{D}_{\mathrm{u}}$ & $5 \mathrm{~dB}$ \\
\hline Inter Site Distance & $512 \mathrm{kbps}$ \\
\hline
\end{tabular}




\subsection{EVALUATION}

For the simulation and evaluation we use Matlab. Shapley value provides the best way for load balancing in a cooperative manner where maximum numbers of cells become satisfied. Our simulation force other cells (which do not want to join in coalition) to join in cooperation. Since all cells in the coalition get benefits, all wish to join in the coalition. In the simulation we consider a small homogeneous network. Some cells cannot be satisfied from our simulation but if we consider for a grand coalition then the number of unsatisfied users decreases.

In some time steps, our proposed algorithm goes slower for evaluation. Since the overloaded cells are congested with load and the number of PRBs are highly busy with the worse SINR. So the neighboring under loaded cell shares its PRBs using this proposed algorithm and decreases the blocking probability of user in an overloaded cell. Thus the handed over user gets a better SINR with useful PRBs from the neighboring cell.

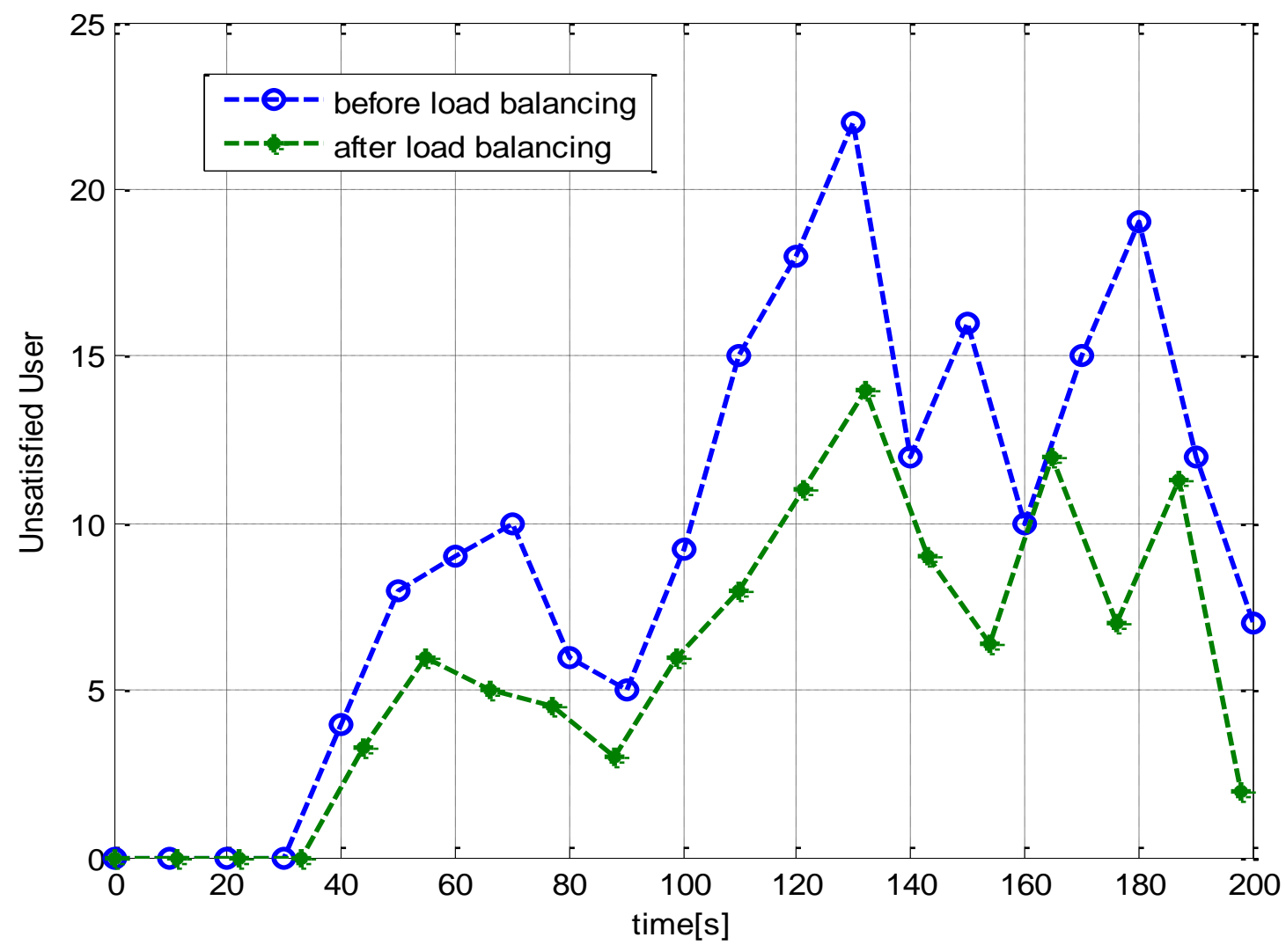

Fig.7. Unsatisfied user vs time

In Figure 5 we observe the unsatisfied users over time steps for before load balancing and after load balancing. We observe that the number of unsatisfied users decreases over time after load balancing due to the availability of free PRBs. From the figure, we notice that the slop is not equal for all cells. Overloaded cells that are much closer to it's under loaded neighboring cell 
will get maximum resources. As a result, the overloaded cell can distribute this resource to its cell.

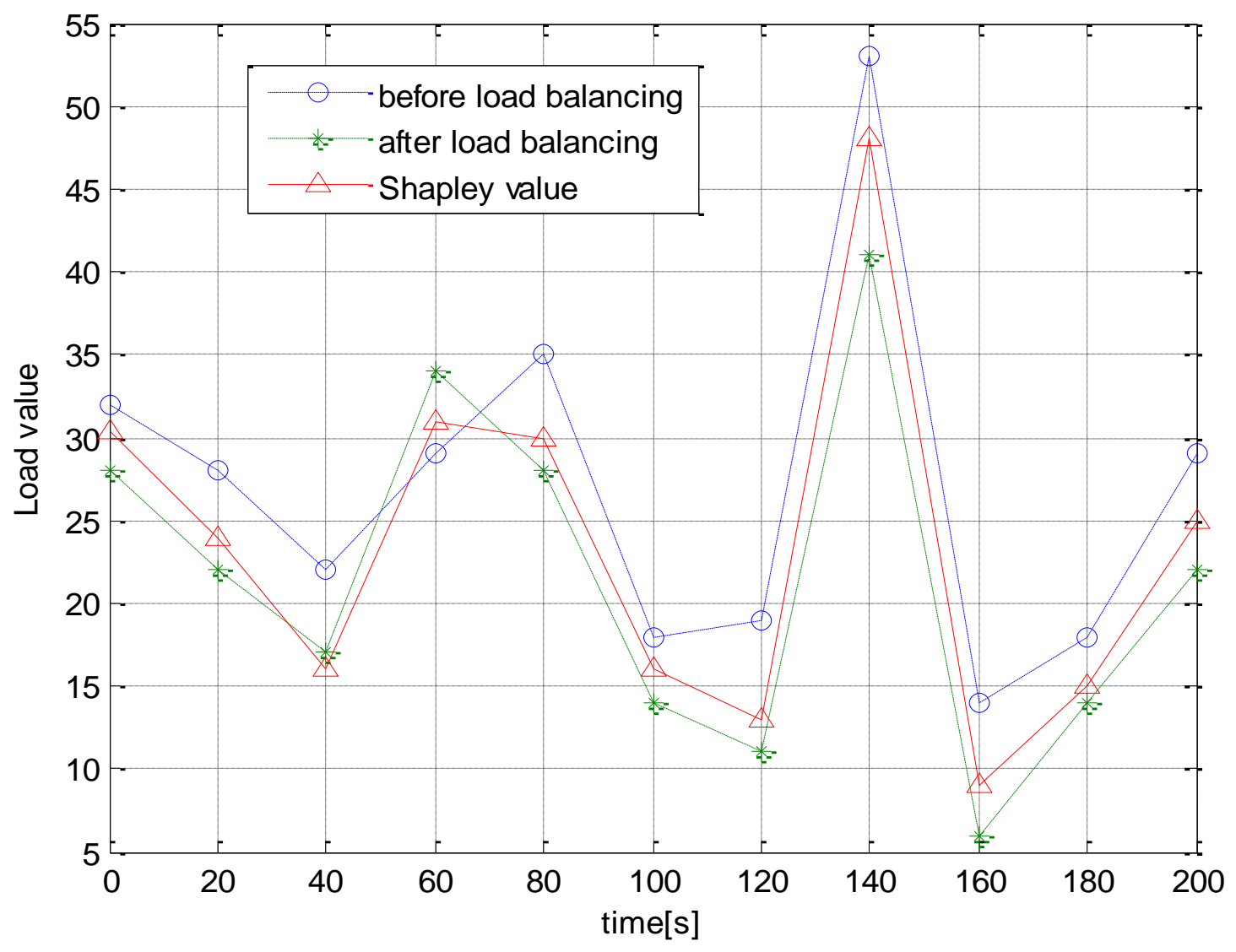

Fig. 8 load value vs time

In Figure 2 we plot load value versus simulation time. From this figure, we can observe that in some cases Shapley value is greater than the present load value (before load balancing) which defines that the cell gets extra load from overloaded cell. In some cases, Shapley value is less than the load value which denotes that the cell is overloaded and will share the load to the under loaded cell. In some cases, Shapley value is closer to the load value which denotes that no more resources are available to share or take. Finally, we notice that after load balancing the Shapley value line is in middle. Since, overloaded cells offload and under loaded cells get this load. So, Shapley value falls in the middle between before load balancing and after load balancing curves. 


\section{CHAPTER 8}

\section{CONCLUSION AND FUTURE WORK}

\subsection{CONCLUSION}

Load balancing is an important research issue for the increased performance in a LTE. Future technology demands a self-organizing algorithm for load balancing which is not vendor specified. In this paper, we propose a self-organized algorithm for load balancing. Our method is based on cooperative game theory which provides a way to allocate the resources efficiently in a distributed network. We compare and evaluate our proposed method before and after load balancing to get the number of satisfied users and the load values. Our simulation results show better performance in terms of satisfied users after balancing the load using our algorithm.

\subsection{FUTURE WORK}

In this thesis,we studied the network layer of LTE using different technique for load allocation.So many aspects have not been considered.This thesis includes the idea for a homogeneous network where aall nodes use the same protocol and the same control procedures from the same vendor.Here for simulation work we have used only MatLab.Our future work will be on Heterogenous network where multiple vendor will be in the same game for cooperation. Where the simulation will be done for the whole network system. 


\section{CHAPTER 9}

\section{REFERENCES}

[1] R. B Myerson, "Game Theory: Analysis of Conflict", Harvard University Press, Cambridge, MA (1991).

[2] E. Rasmusen, "Games and Information: An Introduction to Game Theory", 3rd ed. Blackwell, Oxford (2001).

[3] G. Ein-Ya and M. Maschler, "Insights into Game Theory: An Alternative Mathematical Experience”, Cambridge University Press, Cambridge (2008).

[4] A. MacKenzie, L. DaSilva, and W. Tranter, "Game Theory for Wireless Engineers", Morgan and Claypool Publishers, (Mar. 2006).

[5] J. Cai, and U. Pooch, "Allocate fair payoff for cooperation in wireless adhoc networks using shapley value in processing of International Parallel and Distributed Processing Symposium", Santa Fe, NM, USA, (Apr. 2004), pp. 219-227.

[6] J. VonNeumann and O. Morgenstern, "Theory of Games and Economic Behavior", Princeton, NJ, USA: Princeton University Press, (Sep. 1944).

[7] L. S. Shapley, “A Value for n-person Games”, International Contribution to the Theory of Games, vol. 28, pp. 307-317, (1953).

[8] W. Saad, Z. Han, M. Debbah, and A. Hjørungnes, "A distributed merge and split algorithm for fair cooperation in wireless networks," International Conf. on Communications, Workshop on Cooperative Communications and Networking, Beijing, China, (May 2008).

[9] A. Aram, C. Singh, and S. Sarkar, "Cooperative profit sharing in coalition based resource allocation in wireless networks," IEEE INFOCOM, Rio de Janeiro, Brazil, (Apr. 2009).

[10] L. Shapley and M. Shubik, "The assignment game i: The core," International Journal of Game Theory, vol. 1, pp. 111-130, (1972).

[11] A. E. Roth, "The Shapley value, essays in honor of Lioyd Shapley", Cambridge University Press, (1953).

[12] R. Weber, "Probabilistic Values for games," in the Shapley Value, A.E.Roth (ed.), Cambridge University Press, (1988) 101-120. 
[13] J.Huang, F.Qian, Y.Guo,Y.Zhou,Q.Xu,Z.M.Mao,S.Sen, and O.Spatschek, "ANIn-depth Study of LTE:Effect of Network Protocol and Applicaion Behavior on Performance," In Proceedings of SIGCOMM '13, (Aug. 2013).

[14] S. Kumar, E. Hamed, D. Katabi, and L. E. Li, "LTE Radio Analytics Made Easy and Accessible," in Proceedings of the ACM SIGCOMM, (2014), p. 12.

[15] J. Lee, J.-K. Han, and J. Zhang, "Mimo Technologies in 3GPP LTE and LTE Advanced," EURASIP Journal on Wireless Communications and Networking, vol. 2009, p. 10, (2009).

[16] A. Awada, I. Viering, B. Wegmann, and A. Klein, "Application of Game Theory for Load Balancing in Long Term Evolution Networks," Frequenz Journal of RFEngineering and Telecommunications, vol. 10, pp. 180-184, (2010).

[17] Cai, Jianfeng, and U. Pooch, "Allocate Fair payoff for Cooperation in Wireless Ad hoc Networks using Shapley Value," in Proceedings of the IEEE International Conference on Parallel and Distributed Processing Symposium, (2004), p. 219.

[18] M. Iturralde, T. A. Yahiya, A. Wei, and A. L. Beylot, "Resource Allocation for Real Time Services in LTE networks: Resource Allocation using Cooperative Game Theory and Virtual Token Mechanism," Wireless Personal Communications, vol. 72, pp. 14151435, (2013).

[20] C. Frank and K. Romer, "Algorithms for Generic Role Assignments in Wireless Sensor Networks," in Proceedings of the ACM Conference on Embedded Networked Sensor Systems, (2005).

[21] 3GPP, "Self-configuring and Self-optimizing Network Use Cases and Solutions," TR 36.902, Sophia-Antipolis, France, Tech. Rep., (2005).

[22] A. Lobinger, S. Stefanski, T. Jansen, and I. Balan, "Load Balancing in Downlink LTE Self-optimizing Networks," in Proceedings of the IEEE Vehicular Technology Conference, (2010).

[23] A. Awada, B. Wegmann, I. Viering, and A. Klein, "A Game-Theoretic Approach to Load Balancing in Cellular Radio Networks," in Proceedings of the IEEE International Symposium on Personal, Indoor and Mobile Radio Communications Conference, (2010).

[24] Aumann, R. J. and J. Drèze , "Cooperative Games with Coalition Structures," International Journal of Game Theory 3, (1974) 217-237.

[25] L. Peterson and B. Davie, "Computer Networks: A System Approach", Morgan Kaufmann, (1996).

[26] O. Altrad and S. Muhaidat, "Load Balancing Based on Clustering Methods for LTE Networks," Journal of Selected Areas in Telecommunications, vol. 2, pp. 1-6, (2013). 
[27] J. Eatwell, M. Milgate and P. Newman, “The New Palgrave”, New York, Norton, (1989), pp.8-9.

[28] B. Adam and S. Harborne "Value-Based Business Strategy," Journal of Economics \& Management Strategy, (Spring 1996), Section 7.1, pp.18-19.

[29] 3GPP TS 32.500 V11.00., "Self-Organizing Networks (SON) Concepts and Requirements" (Release 11), 3rd (2011-06).

[30] 3GPP TR 36.902 V9., "Self-configuring and self-optimizing network use cases and solutions", 3.1. (2011-03).

[31] The SOCRATES Project, EB/OL. http://www.fp7-socrates.eu.(2009).

[32] "NGMN use cases related to self-organizing network", overall description, (May 2007).

[33] R. Trestian, O. Ormond and G. Muntean, "Game Theory - Based Network Selection: Solutions and Challenges", Member, IEEE, (2012).

[34] H. Kameda, J. Li, C. Kim, and Y. Zhang, "Optimal Load Balancing in Distributed Computer Systems", Springer Verlag, London, (1997).

[35] T. Roughgarden, "Stackelberg scheduling strategies", In Proc. of the 33rd Annual ACM Symp. on Theory of Computing, pages 104-113, (July 2001).

[36] A. Orda, R. Rom, and N. Shimkin. "Competitive routing in multiuser communication networks", IEEE/ACM Trans. Networking, 1(5):510-521, (October 1993).

[37] E. Altman, T. Basar, T. Jimenez, and N. Shimkin, "Routing in two parallel links: Gametheoretic distributed algorithms" Journal of Parallel and Distributed Computing, (2001).

[38] M. Mavronicolas and P. Spirakis, "The price of selfish routing”, In Proc. of the 33rd Annual ACM Symp. on Theory of Computing, pages 510-519, (July 2001). 


\section{END NOTE}

We would like to end this report by thanking the people that helped us with the research work and add a few pictures.

\section{PUBLICATIONS}

S. Saha \& R. Hossain, “Cooperative Game Theory based Load Balancing”, ICCIE, 2015.

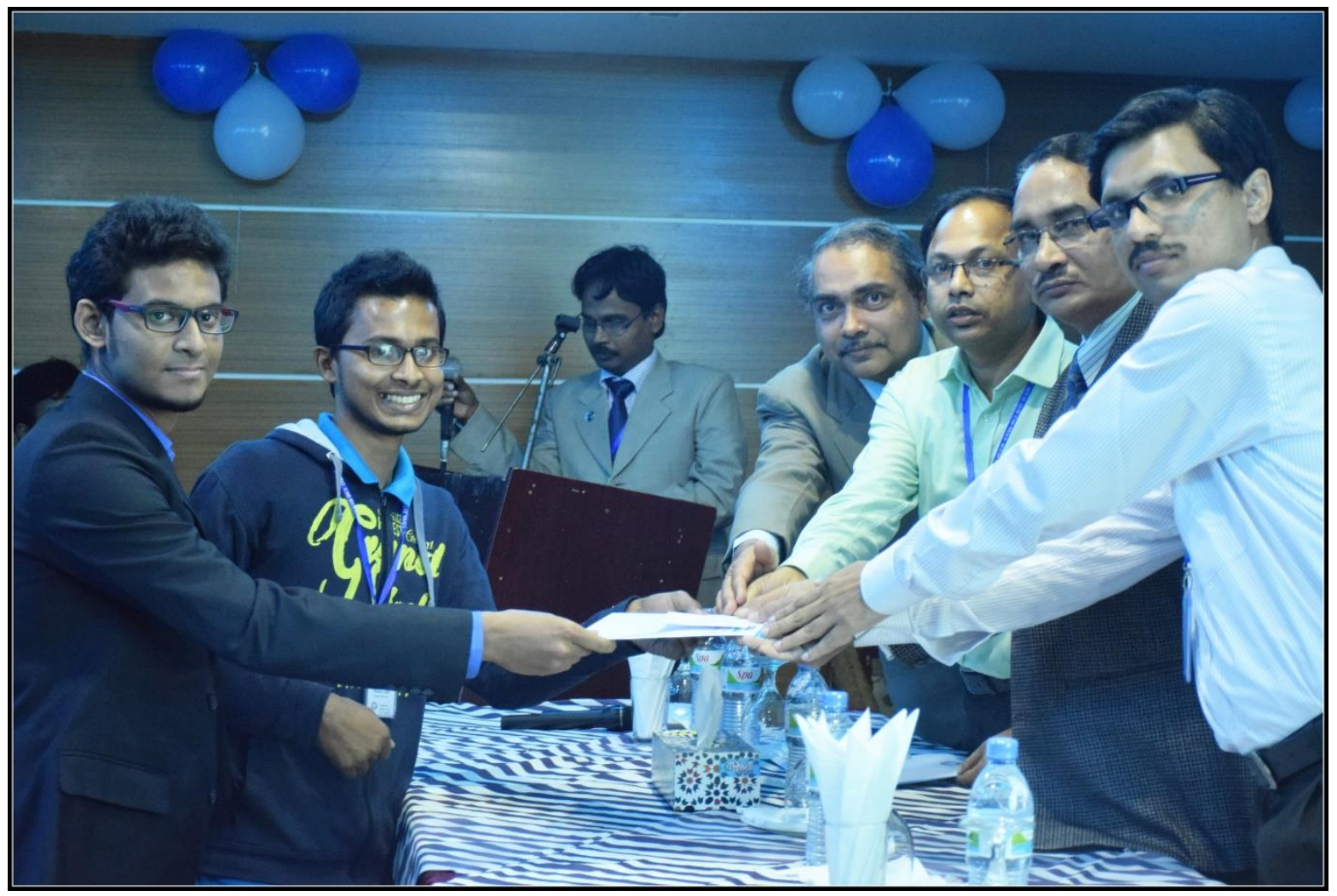

\section{Dr. Fatema Rashid Best Paper Award, ICCIE, 2015.}




\section{RESEARCH DESTINATIONS}

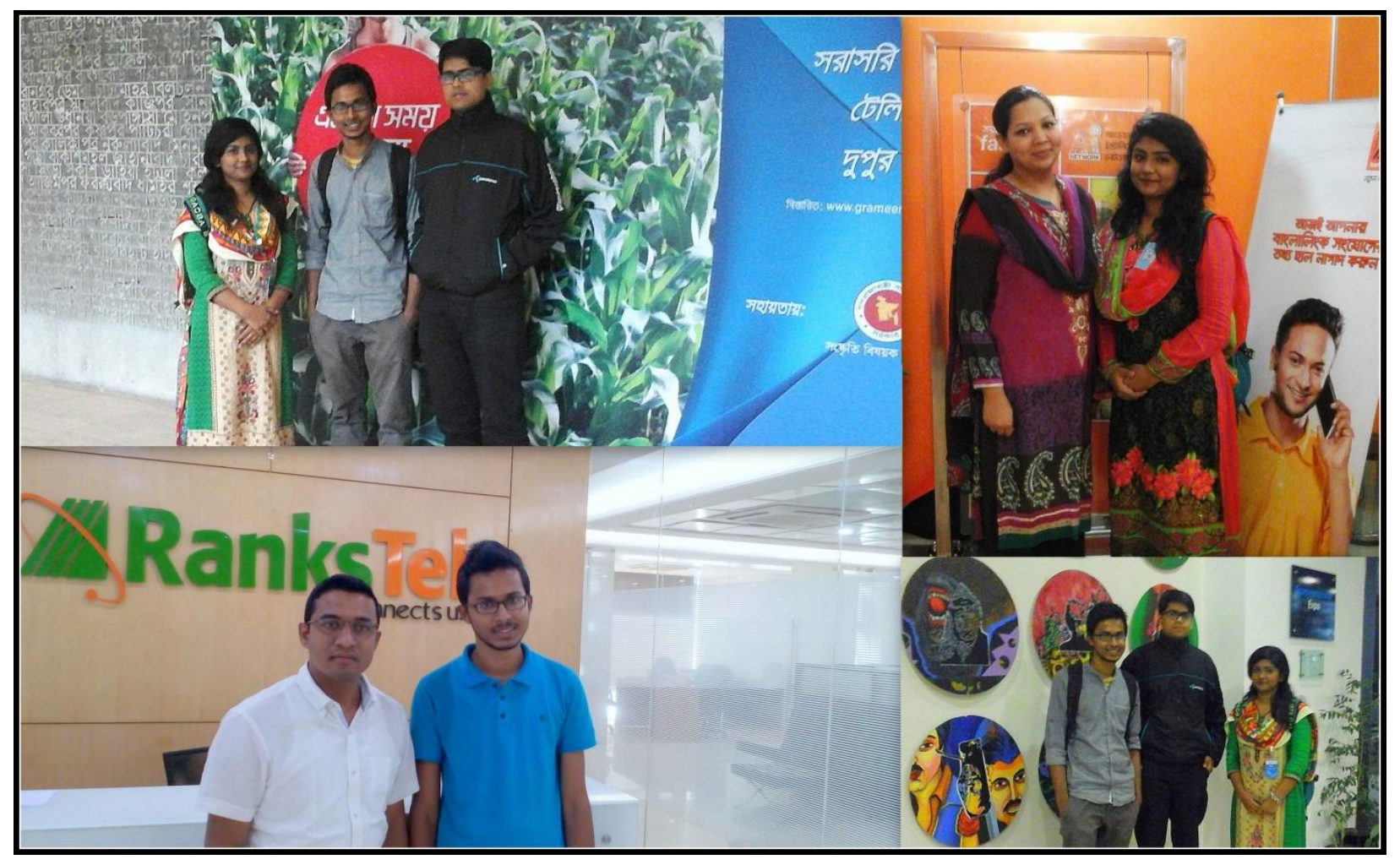

Visit to Grameenphone, RanksTel, Banglalink. 
33 | P a g e 
(C) 2015

Sadia Intesar, Subarno Saha

All Rights Reserved

34 | P a g e 